\section{HYPNOTIC SUGGESTION}

By.S. J. Van Pelt, M.B., B.S. Pp. 95. Bristol: John Wright \& Sons Ltd. 1955. 8s. 6d.

This is an interesting and provocative little book which goes far to raise hypnotism from the esoteric to the scientific. Written expressly for the medical profession, in particular for the general practitioner and those about to specialize in psychological medicine, this book is essentially an original contribution by the author on the nature of hypnotic suggestion and its role in the aetiology and therapy of the psychoneurotic and psychosomatic disorders. The text matter is concise and extremely well laid out; there is an excellent summary of the thesis as a whole and a 94-item bibliography directs the reader to the standard works which support and amplify the author's contentions. The thesis that hypnotic suggestion initiates a psychoneurotic state carries some important implications and those interested in the new techniques of conditioned reflex therapy will find they have much in common with these views, albeit under a different name. In addition to outlining the history, phenomena and nature of hypnotic suggestion and its mechanism in the psychoneuroses the book gives a lucid account of the author's original therapeutic method illustrated with 12 appropriate case histories.

\section{AN INTRODUCTION TO PSYCHIATRY}

By Max Valentine, M.D., D.P.M. Edinburgh: E. \& S. Livingstone Ltd. I955. I5s.

It is not so long ago that a reviewer remarked in this journal on the spate of psychiatric textbooks which had appeared in the last decade. Newcomers must therefore not only be prepared to justify their existence but must,endeavour to be at least different, if not actually superior, to their contemporaries. Some do this by size or scope, others by presentation; this particular volume adopts all three methods to ring the changes.

It has been produced in small format with pliable covers and fits neatly into the pocket - a facility which the tome-burdened student will at once appreciate. In scope it exceeds many of its rivals, for in addition to the traditional classification of psychiatric disorders and therapeutic methods an historical perspective is included together with brief descriptions of personality development, electro-encephalography and clinical psychology. The latter is an extremely neat and lucid exposition if, of necessity, over simplified, while the parts on psychopathy and psycho-analysis deserve special mention for their concision and absence of bias.

The volume is divided into sections instead of chapters and decimal subdivisions are used in place of page numbers. The reviewer is uncertain what advantage is gained thereby but since one subdivision may occupy six pages, finding a reference from the index is six times more tedious than usual. The modern tendency to omit illustrative case histories has been wisely ignored, and in addition the appendix contains II interviews recorded verbatim which do much to put flesh on the bare bones of a psychiatric description. The author has attempted to present psychiatry to the medical reader in a way consistent with his training in applied biological science, his aim being to provide a concise background of factual information and in this he has admirably succeeded.

\section{LECTURES ON THE SCIENTIFIC BASIS OF MEDICINE}

Volume III, r953-54

British Postgraduate Medical Journal. Pp. 398, with nine plates. London: The Athlone Press. I 955 . 35s.

This volume contains $2 \mathrm{I}$ lectures delivered in London in the winter of r 953-54. Many of them are of great interest, such as the introductory one on science and history by Professor Sigerist, of Yale, and the concluding one on experimental psychopathology by R. W. Russell. Others bring together a great deal of recent experimental work not readily available elsewhere, two in particular being F. G. Young's lecture on growth hormone and G. W. Harris's contribution on stress and thyroid activity. Several deal with practical clinical matters more directly, such as L. P. Garrod's lecture on the causes of failure in antibiotic therapys These chapters are mentioned, however, only to indicate the scope of the book; to single out ing dividual contributions when the general standard is so high is perhaps invidious.

\section{STATISTICS OF THERAPEUTIC TRIALS}

By G. Herdan, M.Sc., Ph.D., LL.D. Pp. xvi +

367. London: Cleaver-Hume Press, Ltd. 1955. 5 os.

The importance of statistics in medicine is now widely appreciated and as a result there is an increasing flow of statistical textbooks. Dr. Herdan has written an extremely useful book, as was to be expected from his experience. There is a minimum of mathematical details and the bulk of the work is devoted to practical examples drawn from the field of medicine. A most useful feature is the division of the book into two parts, one being devoted to acute diseases, the other to chronic.

While there will always be some workers who prefer to get a working knowledge of the theory of statistics, the majority will find their needs best met by a book like this, which would allow one to get on with the experiment with the minimum of fuss.

R.H.G.

\section{THE COAGULATION OF BLOOD} Methods of Study

Edited by L. M. Tocantins, M.D. Pp. xv +240 , 웅 illustrated. London: Grune and Stratton Inc. 1955. $\$ 5.75$.

Those not primarily concerned in the field of 